\title{
A STUDY TO FIND OUT THE PREVALENCE OF ASYMPTOMATIC HYPERTENSION IN SCHOOL GOING CHILDREN BETWEEN 5-10 YEARS OF AGE
}

\author{
Balai Chandra Karmakar ${ }^{1}$
}

${ }_{1}^{1}$ Associate Professor, Department of Paediatric Medicine, North Bengal Medical College and Hospital, Darjeeling, West Bengal, India.

ABSTRACT
BACKGROUND
In the past two decades, there has been a conceptual change regarding blood pressure measurement in paediatric age group and
subsequent development of adult essential hypertension. The routine paediatric blood pressure measurement and its national as
well as regional norm publication help us to detect not only fair number of asymptomatic hypertension secondary to formerly
undetected disorder but also establishes that mildly elevated blood pressure during childhood were more common than previously
recognized particularly in adolescents. Hypertension observed in some children secondary to underlying diseases like renal and
endocrine diseases whereas in other cases raised blood pressure may indicate early onset of essential hypertension. Clinically
hypertension in children occurs less frequently than in adults but several evidences support that the roots of essential
hypertension extends back to early childhood. The awareness of regular blood pressure measurement in paediatric age group was
established following publication of first report of the Task Force in Blood Pressure Control on children in 1977. In developed and
industrialized country hypertension is a major public health issue involving approximately $20 \%$ of adult population compared to
paediatric population where the value is 1-3\%. The mortality and morbidity related to hypertension are due to atherosclerosis,
diabetes, cardiovascular and cerebrovascular diseases and end stage renal disease. There is a rising trend of asymptomatic
hypertension among school going children. Keeping this in mind, I have designed this study to find out the prevalence of
asymptomatic hypertension among school going children in Kolkata, WB. The objectives of this study were to determine the
prevalence of asymptomatic hypertension among school going children between 5 -10 years of age, to identify the proper
techniques for blood pressure measurement, to prepare distribution curves of blood pressure by age and sex and to recommend
blood pressure ranges for children denoting normal, high normal and hypertensive for guarding against inappropriate labelling of
hypertensive who are actually not hypertensive.

\section{METHODS}

This is an observational study with cross sectional design done from $(\mathrm{n}=1356)$ OPD of IPGMER \& SSKM Hospital, West Bengal and in different schools of Kolkata among school going children between 5-10 years of age. Blood pressure was measured on the cubital fossa kept at heart level in the seated position on three separate occasions after 10 minutes of rest in a controlled environment using mercury manometer by auscultatory method. The mean of each systolic and diastolic measurement was calculated. The cuff size was selected the basis of actual physical built of the child. Sample size was taken for convenience.

\section{RESULTS}

Total 1356 children were taken of which 681 (50.22\%) were girls and 675 (49.77\%) were boys. Mercury manometer was used to measure blood pressure on three separate occasions at 10 minutes interval in relaxed state. Mean of systolic and diastolic blood pressures were taken for statistical calculation. The overall prevalence of hypertension for systolic and diastolic was $4.12 \%$ and $3.88 \%$ respectively. In my study I found 3.67\% of systolic hypertension (both stage-I and stage-II) and 3.96\% of diastolic hypertension (both stage-I and stage-II) out of 681 girls and $4.59 \%$ of systolic hypertension and 3.70\% of diastolic hypertension out of 675 boys. Percentile distribution of 90th, 95th and 99th and comparison of blood pressure among boys and girls with "p" value were calculated. The overall prevalence of primary and secondary hypertension is $3.68 \%$ and $0.44 \%$ out of total 1356 observations.

\section{CONCLUSIONS}

In all paediatric examinations including office practice, blood pressure should be measured routinely, and monogram must be available to every doctor to classify a case of hypertension or normotension in accordance with age, gender and height. Blood pressure measurement should also be incorporated in school health programme routinely.

\section{KEY WORDS}

Asymptomatic Hypertension, Blood Pressure, School Children

HOW TO CITE THIS ARTICLE: Karmakar BC. A study to find out the prevalence of asymptomatic hypertension in school going children between 5-10 years of age. J. Evolution Med. Dent. Sci. 2019;8(22):1794-1799, DOI: 10.14260/jemds/2019/394

'Financial or Other Competing Interest': None.

Submission 19-03-2019, Peer Review 18-05-2019,

Acceptance 23-05-2019, Published 03-06-2019.

Corresponding Author:

Dr. Balai Chandra Karmakar,

$30 H$ Harey Krista Sett Lane,

P. S. Sinthi, Kolkata-700050, West Bengal, India.

E-mail: balaikarmakar75@gmail.com

DOI: $10.14260 /$ jemds $/ 2019 / 394$

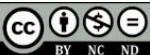

\section{BACKGROUND}

The blood pressure precisely means arterial blood pressure. It is the product of cardiac output and peripheral vascular resistance. The pressure in the aorta, brachial artery and other large arteries rises to a peak value (Systolic pressure) and falls to a minimum value (Diastolic pressure) during each cardiac cycle. The blood pressure is written as systolic over diastolic pressure e.g. 120/80 $\mathrm{mmHg}$. 
Before 1960 serious attention was not given regarding blood pressure measurement in children. In 1977 after the publication of first report of the Task Force on Blood Pressure Control in children by the national Heart Lung and Blood Institute under the chairmanship of Dr. Sidney Blumenthal, clinician started to think about the importance of measurement of blood pressure in children. Subsequently clinician thought children might have elevated blood pressure like that of adults. This necessitated routine blood pressure measurement in children and publication of national as well as regional norms. After that several studies were done in different country and nomograms are available now a day.

Childhood Blood Pressure is Influenced Several Factors. The blood pressure is comparatively lower in children than adults and rises steadily throughout the first two decades of life $1,2,3$. In first day of life, a full-term infant has $70 \mathrm{~mm}$ of $\mathrm{Hg}$ systolic blood pressure (Approximately) and attends $85 \mathrm{~mm}$ of $\mathrm{Hg}$ by the end one month of age ${ }^{1}$. Premature infants have lower blood pressure compare to term infants and this is more related to birth weight than gestational age. Premature infants' blood pressure rises at a faster rate than full-term infant during the first years of life ${ }^{1,2}$. The future risk of adult hypertension is inversely related with birth weight. As children grow during the preschool years, the blood pressure follows a definite pattern: children at a particular percentile of blood pressure distribution trend to maintain that approximate value relative to their peer group as they grow up and the correlation is ranging from 0.30 to 0.66 for systolic blood pressure and 0.12 to 0.57 for diastolic blood pressure during childhood and adolescent period. This pattern follows from adolescence into adulthood which strengthens the hypothesis that essential hypertension begins in childhood, but no one can predict which children will develop essential hypertension in future 4 . Many risk factors have identified as causal association both childhood and adult hypertension. A direct relation has been identified between body weight and blood pressure up to five years of age and the relation is more prominent in the second decade of life. Blood pressure is independently related height in all ages. Race and gender have minimum impact on childhood blood pressure. Boys have slightly higher blood pressure than the girls during the first decade of life and this difference widen during the onset of puberty. A strong familial influence has been identified on blood pressure since in early childhood 4 .

The prevalence of childhood hypertension is comparatively less (1-3\%). ${ }^{5}$ Majority of them have only mild elevation in blood pressure and is belonging to the category of primary (Essential) hypertension. A few children have higher blood pressure (Secondary Hypertension) secondary to underlying diseases. Only about $0.1 \%$ children have documented secondary hypertension and mostly due to renal (80\%) disease. Early diagnosis and intervention as well as effective education and anticipatory guidance may help to improve the future outcome of children and adolescents affected by "silent killer." 4,5

\section{METHODS}

This is an observational study with cross sectional design. Blood pressure was measured by same person (author) and using single instrument. Ethics committee clearance was taken from institution for the study. Consent was taken from both the Parents and school authority concern prior to data collection. The study was carried out from (n=1356) OPD of IPGMER \& SSKM Hospital, West Bengal and in different schools of Kolkata among school going children between 5-10 years of age. Blood pressure was measured on the cubital fossa kept at heart level in the seated position on three separate occasions after 10 minutes of rest in a controlled environment using mercury manometer by auscultatory method. The mean of each systolic and diastolic measurement was recorded. The cuff size was selected the basis of actual physical built of the child. Sample size was taken for convenience.

\section{Inclusion Criteria}

All students from selected schools between 5-10 years of age and healthy children from OPD of IPGME\&R, SSKM hospital.

\section{Exclusion Criteria}

Those children were absent and whose parents were not willing to give consent. Children with pre-existing hypertension or any chronic medical illness like congenital heart disease, liver disease -cirrhosis of liver and portal hypertension, lung disease like asthma etc.

\section{Study Tools}

Blood pressure was measured by auscultatory method and mercury manometer was used to measure blood pressure. The cuff size was selected the basis of actual physical built of the child. Different cuffs viz Child (normal child), Adult (obese child), Thigh cuffs with Bladder width $(\mathrm{cm}) 7.5-9.0,11.5-13.5$, and 18.0-19.0 and Bladder length (cm) 17. 0-19.0, 22.0-26.0, 36.0-38.0 respectively were used to cover (bladder) $40 \%$ (approximately) of arm circumference midway between the acromion and olecranon process. $80 \%$ to $100 \%$ of the arm circumference will be covered by the cuff bladder. Anthropometric measurements were also done. Proforma, SPSS V 20 statistical software and MS excel ultimate edition. Descriptive statistic was used in the proportion of percentage, mean and standard deviation. Comparison of blood between boys and girls was done by unpaired " $t$ "test.

\section{Data Collection}

Phase-I ( $\left.\mathrm{K}_{1}\right)$ of Korotkoff sound was taken as Systolic and Phase-IV (K4) of Korotkoff sound was considered as Diastolic blood pressure. Blood pressure was measured on the cubital fossa kept at heart level in the seated position on three separate occasions after 10 minutes of rest in a controlled environment using mercury manometer by auscultatory method. The mean systolic and diastolic blood pressures were taken for statistical calculation. Cut off value of labelling hypertension is more than $95^{\text {th }}$ percentiles for age, sex and height. Stage I hypertension: SBP or DBP from 95th percentile to 99 th percentile plus $5 \mathrm{~mm}$ to $\mathrm{Hg}$ and Stage 2 hypertension: SBP or DBP greater than 99th percentile plus $5 \mathrm{~mm} \mathrm{Hg}$. So, a child has considered hypertensive if the BP is more than $95^{\text {th }}$ percentile for the age, sex and height. Study was done by convenient sampling technique. The subjects were selected by convenient sampling technique. 


\begin{tabular}{|c|c|c|c|c|c|c|}
\hline \multirow[b]{2}{*}{$\stackrel{8}{\stackrel{8}{*}}$} & \multirow[b]{2}{*}{ 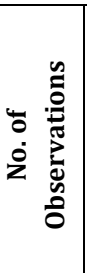 } & \multirow[b]{2}{*}{$\stackrel{×}{凶}$} & \multicolumn{2}{|c|}{ Systolic BP } & \multicolumn{2}{|c|}{ Diastolic BP } \\
\hline & & & 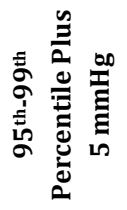 & 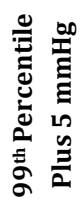 & 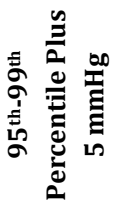 & 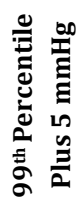 \\
\hline $5 \mathrm{Yr}$. & 151 & $\mathrm{~F}$ & 05 & 00 & 07 & 00 \\
\hline 6 Yr. & 125 & $\mathrm{~F}$ & 05 & 01 & 04 & 01 \\
\hline 7 Yr. & 135 & $\mathrm{~F}$ & 03 & 01 & 06 & 00 \\
\hline $8 \mathrm{Yr}$. & 90 & $\mathrm{~F}$ & 04 & 00 & 02 & 00 \\
\hline 9 Yr. & 90 & $\mathrm{~F}$ & 04 & 00 & 04 & 00 \\
\hline 9 Yr. & 90 & $\mathrm{~F}$ & 04 & 00 & 04 & 00 \\
\hline 10 Yr. & 90 & $\mathrm{~F}$ & 02 & 00 & 03 & 00 \\
\hline Total & 681 & $\mathbf{F}$ & 23 & 02 & 26 & 01 \\
\hline \multicolumn{2}{|c|}{ Prevalence } & $\mathrm{F}$ & \multicolumn{2}{|c|}{$3.67 \%$} & \multicolumn{2}{|c|}{$3.96 \%$} \\
\hline
\end{tabular}

\begin{tabular}{|c|c|c|c|c|c|c|}
\hline \multirow[b]{2}{*}{$\stackrel{\mathscr{0}}{\gtrless}$} & \multirow[b]{2}{*}{ 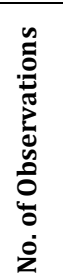 } & \multirow[b]{2}{*}{ ڤ } & \multicolumn{2}{|c|}{ Systolic BP } & \multicolumn{2}{|c|}{ Diastolic BP } \\
\hline & & & 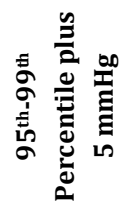 & 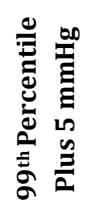 & 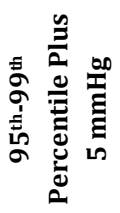 & 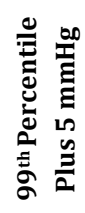 \\
\hline 5 Yr. & 135 & $\mathrm{M}$ & 09 & 00 & 06 & 00 \\
\hline 6 Yr. & 135 & $\mathrm{M}$ & 04 & 01 & 05 & 00 \\
\hline 7 Yr. & 135 & $\mathrm{M}$ & 05 & 00 & 04 & 00 \\
\hline $8 \mathrm{Yr}$. & 90 & $\mathrm{M}$ & 04 & 00 & 02 & 00 \\
\hline 9 Yr. & 90 & $\mathrm{M}$ & 04 & 00 & 04 & 00 \\
\hline $10 \mathrm{Yr}$. & 90 & $\mathrm{M}$ & 04 & 00 & 04 & 00 \\
\hline Total & 675 & $\mathbf{M}$ & 30 & 01 & 25 & 00 \\
\hline \multicolumn{2}{|c|}{ Prevalence } & $\mathrm{M}$ & \multicolumn{2}{|c|}{$4.59 \%$} & \multicolumn{2}{|c|}{$3.70 \%$} \\
\hline \multicolumn{7}{|c|}{$\begin{array}{c}\text { Table 2. Distribution of Systolic and Diastolic Hypertension } \\
\text { Among Boys }\end{array}$} \\
\hline
\end{tabular}

\begin{tabular}{|c|c|c|c|}
\hline Age & Sex & Mean SBP \pm SD & Mean DBP \pm SD \\
\hline 5 Yr. & F & $96.52 \pm 7.51$ & $65.03 \pm 6.35$ \\
\hline 6 Yr. & F & $100.97 \pm 9.76$ & $71.56 \pm 6.86$ \\
\hline 7 Yr. & F & $106.63 \pm 6.90$ & $69.07 \pm 8.58$ \\
\hline 8 Yr. & F & $108.93 \pm 6.68$ & $69.76 \pm 9.30$ \\
\hline 9 Yr. & F & $108.17 \pm 6.45$ & $68.6 \pm 8.25$ \\
\hline 10 Yr. & F & $108.64 \pm 6.49$ & $69.42 \pm 8.99$ \\
\hline
\end{tabular}

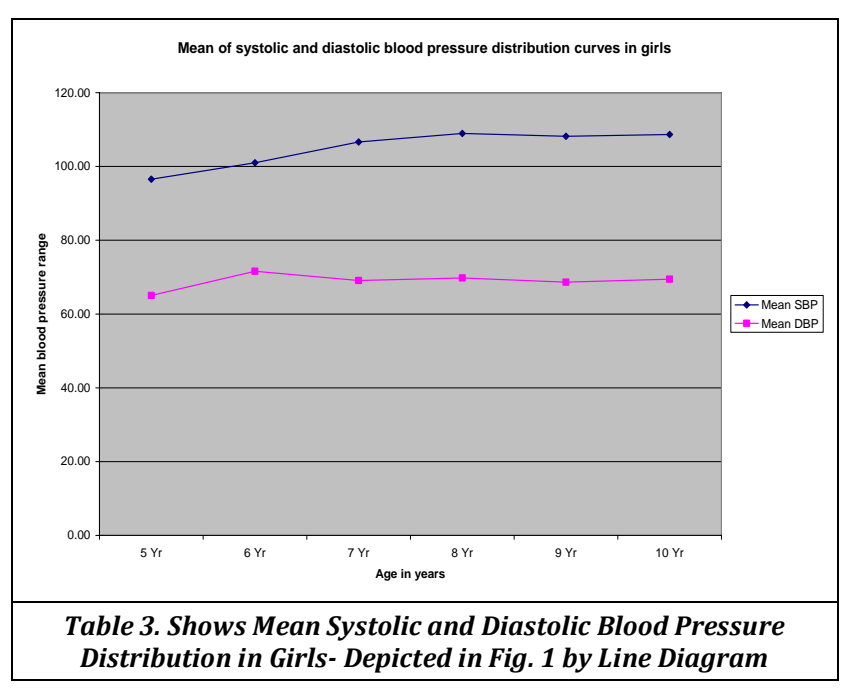

\begin{tabular}{|c|c|c|c|}
\hline Age & Sex & Mean SBP \pm SD & Mean DBP \pm SD \\
\hline 5 Yr. & M & $99.79 \pm 10.54$ & $67.28 \pm 9.95$ \\
\hline 6 Yr. & M & $104.35 \pm 8.36$ & $68.75 \pm 9.40$ \\
\hline 7 Yr. & M & $108.01 \pm 6.33$ & $69.16 \pm 9.04$ \\
\hline 8 Yr. & M & $112.01 \pm 7.12$ & $78 \pm 8.96$ \\
\hline 9 Yr. & M & $108.53 \pm 6.67$ & $69.49 \pm 8.58$ \\
\hline 10 Yr. & M & $108.04 \pm 6.62$ & $68.4 \pm 8.00$ \\
\hline Table 4. Mean Systolic and Diastolic Blood Pressure with Standard \\
Deviation Distribution in Boys \\
\hline
\end{tabular}

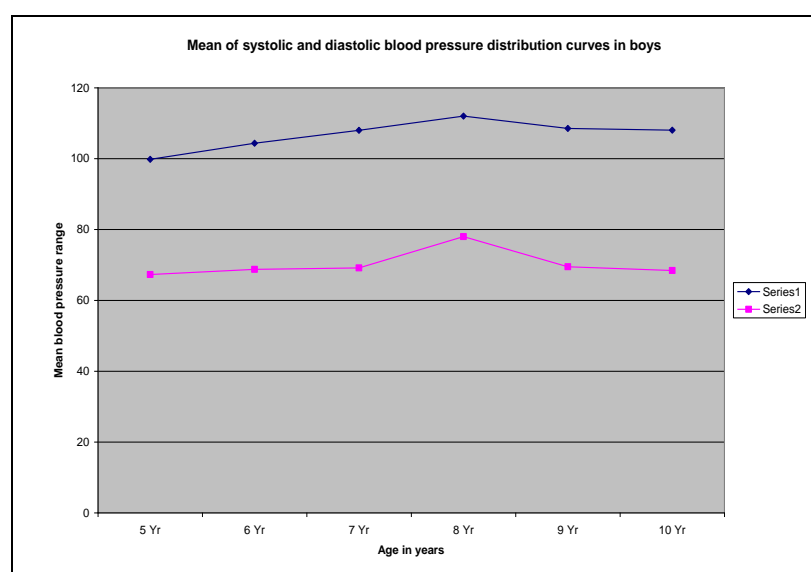

Table 4. Shows Mean Systolic and Diastolic Blood Pressure Distribution in Boys- Depicted in Fig. 2 by Line Diagram

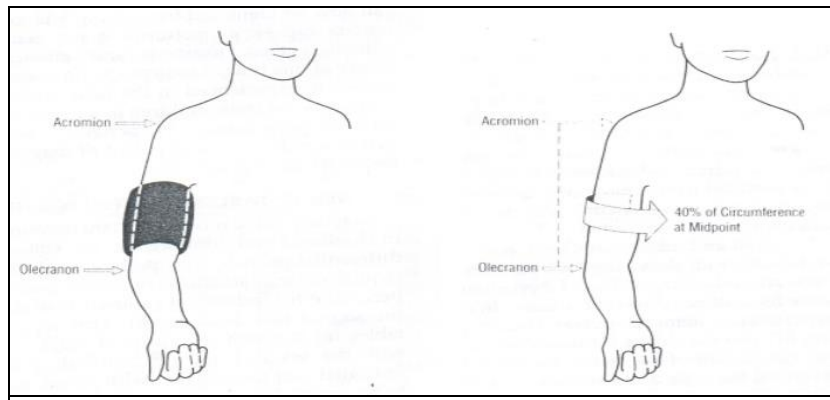

Figure 3. Selection of Proper Cuff Size: Step 1. Width of The Cuff Bladder Approximately Covers $40 \%$ of Circumference of The Arm Measured at a Point Midway Between the Acromion and Olecranon Process. Step $2.80 \%$ to $100 \%$ of The Arm Circumference Will be Covered by Cuff Bladder

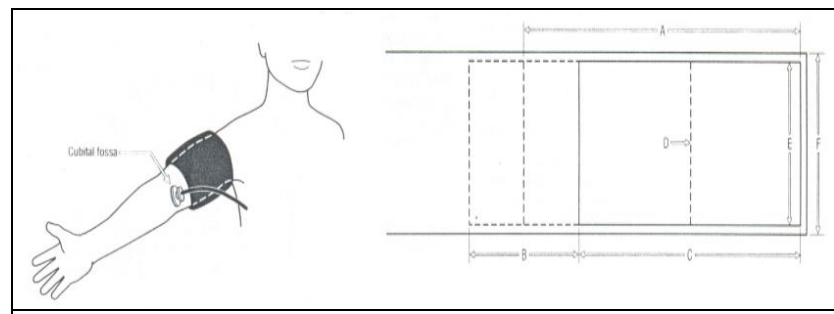

Figure 4. Technique of Blood Pressure Measurement: Blood Pressure to be Measured on the Cubital Fossa Keeping the Arm Supported at Heart Level. The Diaphragm of Stethoscope is Placed Over the Brachial Artery Pulse Proximal and Medial to The Cubital Fossa Below the Lower Edge of The Cuff. The Cuff Size and Dimensions of The Bladder Should be in Accordance with Arm

Circumference. A: Proper Arm Circumference; B: Range of Acceptable Arm Circumference; C: length of Bladder; D: Middle of Bladder; E: Width of Bladder; F: Cuff Width

\section{Statistical Analysis}

Descriptive statistic in the proportion of percentage, mean and standard deviation. Comparison of blood between boys and girls was done by unpaired " $\mathrm{t}$ " test. SPSS V 20 statistical software and MS excel ultimate edition was used for analysis of data. 


\section{RESULTS}

This study is a cross sectional analysis blood pressure of school going children between 5-10 years of age. Total 1356 children were taken of which $681(50.22 \%)$ were girls and $675(49.77 \%)$ were boys. The overall prevalence of hypertension for systolic and diastolic is $4.12 \%$ and $3.88 \%$ respectively.

Table 1 shows numbers of girls having systolic and diastolic blood pressure range $95^{\text {th }}$-99 th Percentile plus $5 \mathrm{~mm}$ of $\mathrm{Hg}$ and $99^{\text {th }}$ Percentile plus $5 \mathrm{~mm}$ of $\mathrm{Hg}$. In my study I find 23 stage-I hypertension (3.37\%) and 2 stage-II hypertension $(0.29 \%)$ for systolic blood pressure and 26 stage-I hypertension $(3.81 \%)$ and 1 stage-II hypertension $(0.14 \%)$ for Diastolic blood pressure out of 681 girl children. Table also shows hypertension is slightly higher in 5 and 6 years of age that may be due to anxiety and fear of the children who did not undergo blood pressure measurement before.

Table 2 shows numbers of boys having systolic and diastolic blood pressure range $95^{\text {th }}$-99th Percentile plus $5 \mathrm{~mm}$ of $\mathrm{Hg}$ and 99th Percentile plus $5 \mathrm{~mm}$ of $\mathrm{Hg}$. In my study I find 30 stage-I hypertension (4.44\%) and 1 stage-II hypertension $(0.14 \%)$ for systolic blood pressure and 25 stage-I hypertension (3.70\%) and no stage-II hypertension for Diastolic blood pressure out of 675 boy children. Table also shows hypertension is slightly higher in 5 and 6 years of age that may be due to anxiety and fear of the children who did not undergo blood pressure measurement before.

The prevalence of primary and secondary hypertension (total $=6$ ) are $3.68 \%$ and $0.44 \%$ out of total 1356 observations and the causes of Secondary hypertension were five Renal (83.33\%), one Endocrinal (16.66\%)) and no Co-arctation of aorta detected.

\section{DISCUSSION}

The concept of childhood hypertension in paediatric practice and subsequent development of essential hypertension in adult has changed significantly during the past two decades. National as well as regional norms of blood pressure are therefore essential for identification of childhood asymptomatic hypertension as blood pressure measurement has been incorporated in routine paediatric examination. This helps to identify more mildly elevated blood pressure and asymptomatic hypertensive cases that were previously undetected. Hypertension detected in some children may be a sign of an underlying disease such as renal parenchymal disease but majority of raised blood pressure in children are due to the early onset of essential hypertension.

Different blood pressures are as follows ${ }^{6}$ :

Systolic Blood Pressure (SBP):

Maximum pressure seen during each cardiac cycle.

\section{Diastolic Blood Pressure (DBP):}

Minimum pressure seen during each cardiac cycle.

\section{Mean arterial Pressure (MAP):}

The average pressure seen throughout the cardiac cycle. $\mathrm{MAP}=\mathrm{DBP}+1 / 3$ Pulse Pressure

Pulse Pressure (PP):

Difference between systolic and diastolic blood pressure.

\section{Divergent Blood Pressure:}

High systolic and low diastolic pressure seen in aortic incompetence.

Normal blood pressure is defined during the first two decade of life as systolic and diastolic blood pressure below the 90th percentile of the distribution for age and sex. High normal blood pressure (Prehypertension) is defined as systolic and diastolic blood pressure between the 90th and 95th percentiles and hypertension is defined as systolic and diastolic blood pressure greater than the 95th percentiles. Recently hypertension has further classified as follows-

\section{Pre-Hypertension:}

SBP or DBP between the 90th and 95th percentiles.

\section{Hypertension:}

SBP or DBP greater than or equal to 95th percentile.

\section{Stage 1 Hypertension:}

SBP or DBP from 95th percentile to 99th percentile plus 5 $\mathrm{mm}$ to $\mathrm{Hg}$.

\section{Stage 2 Hypertension:}

SBP or DBP greater than 99th percentile plus $5 \mathrm{~mm} \mathrm{Hg}$.

A child is labelled as hypertensive when the observed value is more than the cut off value on three separate consecutive measurements after fulfilling all the criteria. Repeated measurement of blood pressure in children shows decrease in value this is due to an accommodation by the child to the measurement environment and procedure or relaxation and/or due to statistical phenomenon of regression toward the mean. Thus, true prevalence of childhood hypertension is significantly lower.

I have taken Phase-IV of Korotkoff sound $\left(\mathrm{K}_{4}\right)$ as diastolic blood pressure as the further and the fifth sounds $\left(\mathrm{K}_{5}\right)$ occur simultaneously and in children the fifth sound many not occur at all. In some children, the Korotkoff sounds can be heard up to $0 \mathrm{~mm} \mathrm{Hg}$ although some study done using fifth phase of Korotkoff sound (K5).7,8

The present study is a cross sectional analysis of blood pressure among school going children between 5 to 10 years of age and sample was taken randomly by convenient sampling technique.

Total 1356 children were studied of which 681 (50.22\%) were girls and 675 (49.77\%) were boys. In my study, I find prevalence of systolic and diastolic hypertension among boys is $4.99 \%$ and $3.70 \%$ respectively and in girls $3.67 \%$ and $3.956 \%$ respectively. The prevalence of systolic and diastolic hypertension is $4.12 \%$ and $3.83 \%$ respectively. The prevalence of stage II hypertension is $0.22 \%$ and stage I hypertension is $3.90 \%$. The prevalence of primary (Total $=50$ ) and secondary hypertension (Total $=6$ ) is $3.68 \%$ and $0.44 \%$ and the causes of Secondary hypertension are five renal $(83.33 \%)$, one endocrinal $(16.66 \%)$ ) and no co-arctation of aorta detected. In this study I find 95th and 99th percentiles of both systolic and diastolic blood pressure among 5 years of boys and girls are higher than that of 6 years followed by gradual increase of systolic and diastolic blood pressure as age advances that strongly correlated with Voors et al study, ${ }^{9}$ Dilermamdo Fazito de Rezende study, ${ }^{10}$ Santo Andre and Purspha Krishna et al study. ${ }^{11}$ The discrepancy in initial rise 
of blood pressure in 5 years in comparison to 6 years may be due to anxiety and fear of the children that had never undergone blood pressure measurement before. The prevalence of hypertension (Systolic) in my study shows $4.99 \%$ in boys and $3.67 \%$ in girls but in Thakor et al study ${ }^{12}$ showed the values are $3.5 \%$ and $0.9 \%$ respectively whereas 3.7\% and 3.1\% in Hashen Y Jaddon et al study,13 9.2 and 9.9\% in H. Ghaunem et al study.14,15 Dilermamdo Fazito de Rezende et al study 10 showed no significant sex difference in prevalence of hypertension. In my study, I find only little sex difference in distribution of systolic and diastolic blood pressure among 5 years and 6 years $(\mathrm{p}<0.0025$ and $\mathrm{p}<0.0029$ for systolic and $\mathrm{p}<0.021$ and $\mathrm{p}<0.006$ for diastolic blood pressure). This discrepancy may be due to inequality of sample size and small number of observations. From 7 years to 10 years percentile distribution of both systolic and diastolic blood pressure reveals no statistical significance ( $\mathrm{p}$ value not significant).

As there is instability of childhood blood pressure, lowest value of all the three consecutive blood pressure measurements is recommended as final value but, in my study, I have taken the mean value for statistical calculation.

Blood pressure during childhood and adolescence is closely related with body size. Children have differential growth velocity so some adjustment is required during interpretation of the blood pressure percentiles for individual children 16,17 . This concept was suggested by second task force report which gives importance to prevent misclassifying of children at the extremes of normal growth such as vary tall children will not be misclassified as hypertensive and very short children with high normal BP or even hypertension will not be missed. ${ }^{7}$ High blood pressure is often not associated with obesity but obesity contributes to higher bold pressure and increased risk for cardiovascular and cerebrovascular diseases. In my study, I have taken detail anthropometric measurements (Height, weight, occipitofrontal circumference and chest circumference) and found elevation of blood pressure strongly associated with increased body mass index that strongly correlated with Bogalusa Heart Study, Verma $M$ et al study, ${ }^{18}$ Thakor et al study, ${ }^{12} \mathrm{H}$, Gharnem et al study,14,15 Jonathan Sofor et al study, Dilermando Fazito de Rezende et al study,10 Dammuls et al study ${ }^{19}$ and Gregory B Luma et al study. ${ }^{20}$

White coat hypertension is a unique concept and found in some children where abnormal blood pressure is seen at the physician's office and normal value is obtained by daytime ambulatory or at home and reverse occurs in white coat normotension (Masked hypertension). This white coat effect is considered significant when the values are more than 20 $\mathrm{mm} \mathrm{Hg}$ and $10 \mathrm{~mm} \mathrm{Hg}$ for systolic pressure and diastolic pressure respectively. The white coat hypertension has been suggested an intermediate cardiovascular risk between normotension and hypertension by some studies with lowest value closure to the risk of normotensive patients. This group of people should be kept under surveillance to prevent future cardiovascular and cerebrovascular complications.

\section{Limitations of The Study}

The study was conducted on 1356 children of 5 to 10 years of age and lower and upper age group was not included. The study population was selected school wise and from OPD; the number of students in each age group is not equal.

\section{CONCLUSIONS}

Routine measurement of blood pressure should be incorporated in all paediatric examinations to classify a case of hypertension or normotension according to age, sex and height. Hypertensive child must be thoroughly investigated and should be treated accordingly in order to prevent future hypertension and related morbidity and mortality.

\section{Ethical Consideration}

The study was approved by IPGMER \& SSKM Hospital, West Bengal ethics committee. Consent was taken from both the parents and concerned school authorities.

\section{REFERENCES}

[1] Lande M. Systemic hypertension. In: Kliegman R, Stanton B, St. Geme III J, et al. eds. Nelson Textbook of Paediatrics. 20th edn. Philadelphia: Elsevier 2016: p. 2294-303.

[2] Kitchiner D. Clinical assessment of heart disease. In: McIntosh N, Helms P, Smyth R, et al. eds. Forfar \& Arneil's Textbook of Paediatrics. $7^{\text {th }}$ edn. London: Churchill Livingstone/ Elsevier 2008: p. 743-7.

[3] Basu S, Srinivasan S. Systemic arterial hypertension in children. In: Parthasarathy A, edr. IAP Textbook of Paediatrics. $4^{\text {th }}$ edn. New Delhi: Jaypee Brothers Medical Publishers (P) Ltd., 2009: p. 538-48.

[4] O'Gara P, Loscalzo J. Physical examination of the cardiovascular system. In: Jameson LJ, Fauci AS, Kasper DL, et al. eds. Harrison's Principles of Internal Medicine. 20 $0^{\text {th }}$ edn. New York City: McGraw-Hill Education 2018: p. 4195-207.

[5] Gulati, Sanjeev. Hypertension in children. Indian Journal of Pediartics 2002;69:1077-81.

[6] Barrett K, Boitano S, Barman S, et al. Blood as a circulatory fluid \& the dynamics of blood \& lymph flow. Ganong's Review of Medical Physiology. 23rd edn. United States of America: The McGraw-Hill Companies, 2010: p. 521-53.

[7] Task Force on Blood Pressure Control in Children. Update on the 1987 Task Force Report on high blood pressure in children and adolescents: a working group from National High Blood Pressure Education Program. On hypertension control in children and adolescents. Paediatrics 1996;98:64958.

[8] Cook NR, Gillman MW, Rosner BA, et al. Prediction of young blood pressure from childhood blood pressure, height and weight. J Clin Epidemiol 1997;50(5):571-9.

[9] Voors AW, Foster TA, Frerichs RR, et al. Studies of Blood pressure in children, ages 5-14 years in a total biracial community: The Bogalusa Heart Study. Circulation 1976;54(2):319-27.

[10] De Rezende DF; Scarpelli RAB, De Souza GF, et al. Prevalence of systemic hypertension in students aged 7-14 years in the municipality of Barbacena, in the state of Minas Gerais. Arg Bras Cardiol Sao Paulo 2003;81(4):375-86. 
[11] Krishana P, PrasannaKumar KM, Desai N, et al. Blood pressure reference table for children and adolescents of Karnataka. Indian Paediatrics 2006;43(6):491-501.

[12] Thakor HG, Kumar P, Desai VK. An epidemiological study of hypertension amongst children from various primary schools of Surat city. Indian Journal of Community Medicine 1998;23(3):110-15.

[13] Jaddou HY. Blood pressure profile in school children and adolescents in Jordan. The Queen Alia heart Institute, March 2000.

[14] Ghaumen H. Study of cardiovascular disease risk factors among urban school children in Sousse, Tunisia. Eastern Mediterranean Health Journal 2000;6(5/6):1046-54.

[15] Ghannem H, Trabelsi L, Gaha R, et al. Study of cardiovascular disease risk factors among rural school children in Sousse, Tunisia. Eastern Mediterranean Health Journal 2001;7(4-5):617-24.
[16] Task Force on Blood Pressure Control in Children: Report of the Second Task Force on Blood Pressure Control in Children -- 1987. Paediatrics 1987;79:125.

[17] National High Blood Pressure Education Program Working Group on high blood pressure in children and adolescents. The fourth report on the diagnosis, evaluation and treatment of high blood pressure in children and adolescents. Paediatrics 2004;114(2 Suppl 4th report):555-76.

[18] Verma M, Chhatwal J, Geroge SM. Obesity and hypertension in children. Indian Paediatrics 1994;31(9):1065 -9.

[19] Gidding SS, Nehgme R, Heise C, et al. Severe obesity associated with cardiovascular deconditioning, high prevalence of cardiovascular risk factors, Diabetes mellitus/hyperinsulinemia and respiratory compromise. J Pediatr 2004;144(6):766-9.

[20] Luma GB, Spiotta RT. Hypertension in children and adolescents. AM Fam Physicain 2006;73(9):1158-68. 